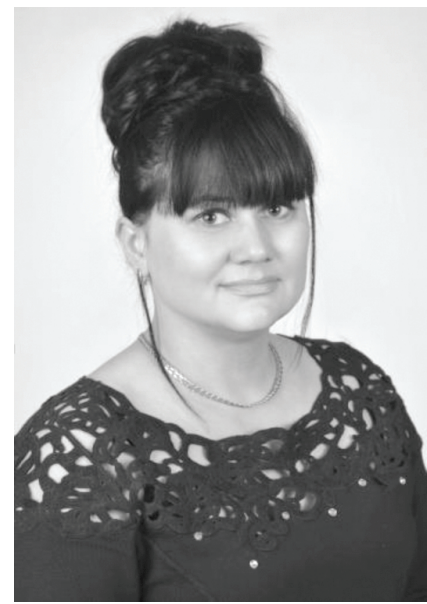

Natalija Lytovchenko - filologijos mokslų daktarè,

Klaipèdos universiteto mokslo darbuotoja

Moksliniai interesai: rusų literatūra, pasaulio

literatūra, kultūra ir istorija, literatūros teorija

El.paštas: Skarlett75@mail.ru

Nataliia Lytovchenko - PhD in Humanities, researcher of Klaipeda University

Research interests: Russian literature, world

culture, world history, literatury theory

E-mail: Skarlett75@mail.ru

\title{
Наталия Литовченко
}

Klaipedos universitetas

\section{ТЕ ОРЕ Т ИК О-МЕ Т ОДО ЛОГИ ЧЕ С К И АСПЕКТЫ ИЗУЧЕНИЯ МОТИВОВ И ОБРАЗОВ В ПОЭТИЧЕСКИХ ТЕКСТАХ}

\section{Anotacija}

Straipsnyje nagrinejjama meno kūrinio motyvų analizès problema. Bandoma sujungti esamas motyvų analizès teorijos kryptis, taip pat - nubrěžti perspektyvias tolesnių tyrimų kryptis. Atskleisti pagrindiniai principai, kuriais literatūrinių kategorijų sistemoje grindžiamas terminas motyvas. Atlikus analizę, suformuoti kriterijai, pagal kuriuos galima atpažinti dominuojančius motyvus poezijoje.

PAGRINDINIAI ŽODŽIAI: motyvas, motyvo struktūra, motyvo analizė, simboliai, poetinė sistema.

\section{Аннотация}

В статье исследуется проблема анализа мотивов художественного произведения. Делается попытка объединить существующие направления в теории анализа мотива, а также наметить перспективные направления дальнейших исследований. Выявляются основные принципы, на которых базируется термин «мотив» в системе литературоведческих категорий. В результате анализа сформированы критерии выделения доминантных мотивов в поэтическом творчестве.

КЛЮЧЕВЫЕ СЛОВА: мотив, мотивная структура, мотивный анализ, символы, поэтическая система.

DOI: http://dx.doi.org/10.15181/rh.v28i0.2235 
Цель данной статьи - рассмотреть современные теории мотива, понятийный аппарат проблемного поля «мотив», имманентный природе поэтического текста; проанализировать специфику функционирования термина «мотив» в системе литературоведческих категорий, опираясь на современные теории мотива русскоязычных авторов.

Мы солидарны с теми исследователями, которые считают, что «в лирике круг мотивов наиболее отчетливо выражен и определен, поэтому изучение мотивов в поэзии особенно плодотворно» (Литературный энциклопедический словарь 1987, 230). Как известно, мотив может быть выделен как в пределах одного или нескольких произведений поэта (например, определенного цикла), так и в контексте всего его творчества, литературного направления.

Анализ научной литературы позволяет утверждать, что теория мотива представлена в основном несколькими концепциями и их «вариациями» с учетом эволюции данной категории. Это семантическая теория, берущая начало в исторической поэтике А. Веселовского, а также более поздние дихотомическая, структурно-семантическая, тематическая, интертекстуальная, прагматическая теории мотива (см. об этом: Силантьев 2004, 3942; 67-72). Данные концепции глубоко и всесторонне освещены в работах И. Силантьева в историографическом, содержательном и сопоставительном аспектах (Силантьев 2011, 106-114; 183, 184). В настоящее время это наиболее авторитетные источники, к которым обращаются практически все, пишущие о мотиве.

Отдельные аспекты теории мотива рассматриваются в литературоведческих (Н. Тамарченко, Ю. Шатин, В. Хализев, Л. Целкова, Э. Бальбуров, В. Тюпа), фольклористских (Б. Путилов, С. Неклюдов, Н. Черняева, Н. Криничная), лингво-когнитивных и семиотических (О. Костина-Кассанелли, А. Тарабакина) исследованиях, что свидетельствует о междисциплинарности категории и соответственно о различных подходах к изучению мотива. В работах решаются вопросы различного уровня сложности, многие из которых являются дискуссионными или имеют постановочный характер. Так, несмотря на более чем вековую традицию изучения мотива, до сих пор четко не определен сам термин, его специфика в драматических и лирических текстах, остаются не до конца проявленными критерии вычленения мотива. Недостаточно разработаны такие важнейшие теоретические понятия, как мотивная структура, мотивное ядро, мотивный анализ. Как правило, они употребляются как само собой разумеющиеся без терминологического объяснения или в качестве научной метафоры. Мало изучены корреляции понятий мотив и символ; мотив и образ и другие. 
Bсе это позволяет констатировать: несмотря на устойчивый интерес литературоведов к данному понятию, мотив, как справедливо замечено С. Неклюдовым, по-прежнему «относится к числу наиболее сложных для изучения предметов филологического исследования. Он трудноуловим и трудноопределим, неясно соотношение его синтагматических и парадигматических ракурсов, морфологической схемы и текстовой реализации, универсальных структур и национально специфических редакций, его корреляций с компонентами модели/картины мира, с одной стороны, и с «общими местами» текста, locicommunes, с другой» (Неклюдов 2004, 236). Перечисленные проблемы в тех или иных аспектах и объеме рассматриваются в кандидатских диссертациях, посвященных изучению поэтических систем (Пахарева 1994, 66, 61, 63). Однако полученные результаты пока еще не систематизированы и не вписаны в общую теорию лирического мотива.

Термин «мотив» широко используется в разных методологических контекстах, возможно, поэтому существуют расхождения в толковании понятия и описании его характеристик. Достаточно широкий диапазон определений мотива также может объясняться его структурной открытостью и пластичностью. Так, мотив легко взаимодействует с такими составляющими художественного мира произведения, как сюжет, тема, персонаж, хронотоп, лейтмотив, что достаточно полно и глубоко раскрыто исследователями (О. Фрейденберг, Е. Мелетинский, Б. Томашевский, И. Силантьев, А. Жолковский, Ю. Щеглов, Б. Гаспаров, В. Тюпа). В последние годы появляются работы, которые охватывают новые ракурсы проблемы. Так, изучается смысловое соотношение литературного мотива и культурного концепта как двух базовых понятий филологии и когнитивной лингвистики, их взаимодействие в методиках изучения современного поэтического текста (Костина-Кассанелли 2013, 59-63).

Или, например, устанавливается взаимосвязь, сходство и различие между мотивом и мифологемой (Иванова 2003), проясняется корреляции мотива с поэтически миром автора (Волкова 2001).

Для изучения лирических мотивов особое значение имеет проблема корреляции / разграничения мотива и символа, которая практически не изучена. Она лишь обозначена в работах И. Силантьева «Поэтика мотива» (Силантьев 2004, 120-121), Н. Меднис «Мотив воды в романе Достоевского «Преступление и наказание» и др. Разграничение мотива и символа, которые «часто имеют общие корни», Н. Меднис совершенно справедливо называет«трудно решаемой проблемой» (Меднис 134]. Общие корни символа и мотива, с точки зрения литературоведа, берут начало в «коллективном бессознательном», то есть архетипах (Меднис 134), что, дополним, не 
исключает сознательного заимствования в художественном тексте мотива, темы или ее части из мифологических источников. Н. Меднис акцентирует функциональную «двуликость» архетипа, который «сохраняет черты архетипа на уровне авторского бессознательного и становится мотивом, отчуждаясь и объективируясь в художественном тексте в качестве одного из элементов эстетической системы» (Меднис 137). Иными словами, если выйти в другую систему дефиниций, речь идет об инвариантных и вариантных компонентах мотива, которые подвижны и определяются контекстом. Автором подчеркиваются эстетические функции мотива, что является актуальным для исследования поэтических мотив.

Несколько иной точки зрения придерживается И. Силантьев. Со ссылкой на работы Ю. Лотмана он определяет связь мотива и символа следующим образом: «Мотив как знак художественного языка является вторичным культурным знаком. Это знак, в котором первичные вариантные семантические признаки, обусловленные непосредственными контекстами фабулы и сюжета, являются планом выражения для вторичных инвариантных семантических признаков, в своей совокупности составляющих функцию мотива. В этом можно видеть структурное сходство мотива как знака с символом, который также сочетает в себе два различных плана означаемого, одновременно и подобных друг другу и несводимых один к другому (Лотман 2005, 240-250). И наоборот, символ оказывается функционально близок мотиву в своей «сюжетогенной» функции (Лотман 2005, 120). Прокомментировать данный тезис можно так: символ и мотив имеют точки соприкосновения по двум указанным здесь параметрам: структурному - имеются в виду их двуплановость и функциональному - сюжетообразующая функция. И с этим трудно не согласиться. Однако по-прежнему остается открытым вопрос о критериях вычленения мотива, поскольку четко не проявлены его отличия от символа или, например, от образа. Эта проблема заявляет о себе особенно ярко, если продолжить логику рассуждений И. Силантьева и рассматривать образ «как знак, то есть средство смысловой коммуникации в рамках данной культуры или родственных культур» (Литературная энциклопедия терминов и понятий 2003, 669).

Несмотря на то, что уже в первых работах, посвященных теории мотива, упоминается о корреляции понятий мотив и образ (А. Веселовский, О. Фрейденберг, Е. Мелетинский, Б. Ярхо), проблема не получила системного разрешения. Чаще всего речь идет об его взаимосвязи с персонажем или лирическим субъектом. Между тем полезно выявить различие между словесным или предметным образом и мотивом для его выделения в по- 
этических текстах. Отметим, что такого рода попытки зафиксированы в новейших исследованиях (Вершинина 2008, 8-10).

Так, опираясь на работу Б. Ярхо «Методология точного литературоведения: Набросок плана» (Ярхо 2006, 6-65), исследователи обращают внимание на его определение мотива как «образа в действии или состоянии» (Ярхо 2006, 42). В результате формулируется вывод о том, что для Б. Ярхо «основой для выделения мотива послужили его связи с образом» (Вершинина 2008, 10). И далее: «Диссертант опирается на эту точку зрения о соотношении мотива и образа: мотив, который не всегда явлен в тексте, чаще всего раскрывается посредством проявленных в произведении образов, способствующих его раскрытию» (Вершинина 2008, 57). Сама по себе точка зрения привлекательна и не вызывает возражений в целом, но насколько она вытекает из работы Б. Ярхо? Для объективности картины приведем это высказывание полностью: «С вопросом о «мотивах» мы вступаем в область теории сюжета, тематики. Определяя мотив, как образ в действии (или состоянии) (разрядка автора - Б. Ярхо), я, кажется, верно передаю тот смысл, который большинство специалистов по истории сюжета вкладывают в этот термин. Мотив, т(аким) обр(азом), есть некое деление сюжета, границы коего исследователем определяются произвольно» (Вершинина 2008, 42). На примере романа Пушкина «Евгений Онегин» литературовед показывает, как «работает» этот принцип. Иными словами, Б. Ярхо рассматривает мотив прежде всего в его взаимосвязях с сюжетом в аспекте предикативности, то есть «действия» или «состояния». В пользу данного тезиса свидетельствует дальнейшая аргументация ученого. Опуская некоторые ее звенья (например, рассуждения о невозможности установить точные границы мотива, о том, что «мотив не есть реальная часть сюжета, а рабочий термин»), остановимся на главном. Б. Ярхо отказывает литературному мотиву в семантическом и образном статусе, сведя его к некоему рабочему термину, к абстракции, лишенной конкретики, без которой немыслим художественный образ. Это особенно наглядно, если вспомнить, что сам Б. Ярхо определяет образ как «такое значение слова, которое вызывает представление о чувственном или эмоциональном восприятии» (Ярхо 2006, 42).

Литературовед предлагает «транспонировать идейные величины в языковые. Если мотив есть образ в действии, то действие это выражается сказуемым (глагол или nomenactionis), напр(имер), «герой сватается», или «сватовство героя» (Ярхо 2006, 43). Следовательно, на первый план выводится функция мотива, а не его образность. Кроме того стороннику «точного литературоведения» трудно смириться с «произвольностью» выделения и называния мотива. Наиболее близкой мотиву, по мысли ученого, является 
тема, которая сочетается с мотивом также по принципу «произвола» (Ярхо $2006,44)$. Таким образом, трудно согласиться с выводом диссертанта «о соотношении мотива и образа» в работах Б. Ярхо, поскольку она базируется, как свидетельствует автореферат, на «осколочной» цитате. На наш взгляд, контекст в его многоаспектности гораздо сложнее. Возможно, в тексте диссертации эти связи между мотивом и образом представлены не столь прямолинейно.

Действительно, нет сомнения в том, что связь между мотивом и образом существует. Она зафиксирована теорией мотива А. Н. Веселовского, отмечающего «образный одночленный схематизм» мотива (Веселовский 1989, 301). Об этом пишут современные исследователи, рассматривающие взаимосвязи между мотивом и темой. Основное отличие они видят в том, что «мотив, в отличие от темы, имеет непосредственную словесную (и предметную) закрепленность в самом тексте произведения; в поэзии его критерием служит наличие ключевого, опорного слова, несущего особую смысловую нагрузку (дым у Тютчева, изгнанничество у Лермонтова)» (Лермонтовская энциклопедия 1981, 230). Таким образом, изучение и анализ источников позволяет предложить один из критериев разграничения мотива и символа. Как представляется, по сравнению с контекстуальной многоплановостью и полисемантичностью символа, мотив моносемантичен, даже, несмотря на то, что он может быть наделен подтекстом. При этом следует признать их гибридные формы, например, символический мотив.

Наиболее емко отношения между образом и мотивом объясняет М. Эпштейн. В своих рассуждениях он исходит из степени обобщенности образа в его условной, культурно выработанной форме и называет три типа образов: образ-мотив; образ-топос; образ-архетип. Исследователь особо подчеркивает их интертекстуальную природу, поскольку «они характеризуются устойчивостью собственного употребления, выходящего за рамки одного произведения» (Эпштейн 1987, 254). Его определения мотива через образ продолжает традицию Б.Томашевского, несколько усиливая эту связь, поскольку между образом и мотивом практически поставлен знак равенства. Итак, по Эпштейну, «мотив - это образ, повторяющийся в нескольких произведениях одного или многих авторов, выявляющий творческие пристрастия писателя или целого художественного направления» (Литературный энциклопедический словарь 1987, 254). В качестве примера названы образы-мотивы метели и ветра у А. Блока, дождя и сада у Б. Пастернака, углов и порогов у $\Phi$. Достоевского и др. Иными словами, мотив характеризуется двойственностью: с одной стороны, подчеркнута индивидуальнотворческая специфика мотива, с другой - его устойчивость и вездесущность 
«схемы» или «формулы». Отсюда задача интерпретатора - «сопоставление отдельных мотивов и словесных образов» для выявления «художественного построения мысли» (Лермонтовская энциклопедия 1981, 291).

Сложность и широкий диапазон дефиниции «мотив» отмечает В. Хализев, утверждая, как и другие исследователи, причастность, но отнюдь не тождественность мотива теме и концепции (идее) (Хализев 2000, 266). Однако в отличие, например, от И. Силантьева или Б. Ярхо литературовед не считает предикативность одним из основных признаком идентификации мотива. По его мнению, присутствуя в самых разных формах, мотив «может являть собой отдельное слово или словосочетание, повторяемое и варьируемое, или представать как нечто обозначаемое посредством различных лексических единиц, или выступать в виде заглавия либо эпиграфа, или оставаться лишь угадываемым, ушедшим в подтекст» (Хализев 2000, 266). Как видим, в приведенном высказывании отсутствует жесткая структурная и функциональная регламентация мотива. На первый план выдвигается его семантическая и лексическая оформленность, близость мотива теме произведения (может «выступать в виде заглавия»), его характерной чертой является повторяемость, что особенно важно учитывать при анализе поэтических текстов. В результате В. Хализев предлагает такое определение мотива: «Это компонент произведений, обладающей повышенной значимостью (семантической насыщенностью)» (Хализев 2000, 266). Данный тезис литературовед иллюстрирует функционированием словесных мотивов в лирической поэзии А. Блока, которые выражены номинативно - ключевыми словами (Хализев 2000, 268).

Показателен еще один вариант оформления мотива, с точки зрения В. Хализева также имеющий право на существование. Так, «мотивами нередко называют темы и проблемы творчества писателя (например, нравственное возрождение человека; алогизма существования людей)» (Хализев 2000, 268). И с этим нельзя не согласиться.

Дефиниция мотива, предложенная В.Хализевым, перекликается с формулировками в других исследованиях. Так, в Dictionary of Word Literary Terms / by J. Shipley мотив определяется как «слово или мыслительная модель, повторяющиеся в одинаковых ситуациях или для того, чтобы вызвать определенное настроение внутри одного произведения или в различных произведениях одного жанра» (A Dictionary of Modern Critical Terms 1987). То есть акцентируются такие компоненты мотива, как его повторяемость, способность к выражению в номинативной или логической форме, эмоционально-эстетическая наполненность, жанровая обусловленность, что особенно характерно для лирических мотивов. 
Жизнеспособность такого рода теоретических построений подтверждается исследовательской практикой. Так, в одной из первых в украинской русистике работ, в которой рассматривается мотивная структура лирики Анны Ахматовой, для описания итоговой схемы мотивного ядра Т. Пахаревой систематизированы темы, лейтмотивы, мотивы, номинированные в виде ключевых слов («простейших словесных формул») (Пахарева 1994, 96]. Данный подход подчеркивает такую особенность мотива, как его содержательно-структурное единство, которое сохраняется при различных вариантах словесного выражения. Выявленные закономерности позволяют прийти к еще одной особенности мотива, пунктирно обозначенном в теории мотива Б. Ярхо.

Как представляется, следует говорить о дуальности мотива, которая зафиксирована в таком определении: «Мотив - устойчивый формально-содержательный компонент художественного произведения, критического или литературоведческого труда» (Літературознавча енциклопедія 2007, 78). Иными словами, в зависимости от интенций мотив функционирует как текстуальная структура и как инструментарий изучения текста. По-видимому, этим фактором могут объясняться формулировки мотивов в виде логико-семантических конструкций, например, «экзистенциальные мотивы», «эсхатологические мотивы», мотив «непротивления злу насилием», чеховские мотивы, мотив «вечного возращения» и т.д. В словарной статье перечислены некоторые формы бытования мотивов в художественном тексте: «Мотивами могут быть чувства, переживания, представления, мысли, понятия, идеи, интересы, ориентированные на определенную цель» (Літературознавча енциклопедія 2007, 78). То есть за формальной стороной мотива признается его значительный семантический потенциал. Также мотив может быть выражен «в смысле повторяющегося в творчестве поэта комплекса чувств, переживаний, идей, его лейтмотива (В. Дибелиус)» (Літературознавча енциклопедія 2007, 78), что особенно важно для понимания специфики лирического мотива.

Проведенный анализ позволяет констатировать, что, несмотря на глубокое и всестороннее рассмотрение взаимосвязей лирического мотива с другими литературоведческими категориями, вопрос его терминологической четкости и критериев идентификации в поэтических текстах остается открытым.

Большинство литературоведов, исследующих теорию мотива, пытаются найти как сходство, так и различия между повествовательным и лирическим мотивами, а иногда и описать последний посредством такого сопоставления. Так, общей характеристикой мотива, независимой от родовой 
специфики произведения, И. Силантьев считает предикативность. По его мнению, она не учитывается теми учеными, которые «под мотивом нередко подразумевают любой повторяющийся элемент текста, выделяющийся устойчивой и характерной для данной поэтической традиции семантикой и устойчивым вербальным выражением» (Пахарева 1994, 106). По логике исследователя, это является причиной расширительного - «без берегов»толкования дефиниции, когда под категорию мотива подпадает «все, что повторяется в тексте и из текста в текст, будь то образ, деталь, какой-либо характерный стилистический штрих или просто слово» (Силантьев 2011, 106).

Как представляется, в данном высказывании содержится скрытая полемика с Б. Гаспаровым. В определении литературного лейтмотива (мотива) исследователь исходит из иного - тыняновского понимания сюжетной динамики. Отсюда поэтический мотив, мотивная цепь в лирике и в прозе XX века, тяготеющей к лейтмотивным построениям, для Б. Гаспарова обладают особыми характеристиками по сравнению с традиционно понимаемым эпическим мотивом. Здесь на первый план выдвигается способность мотивов (лейтмотивов) диалогически взаимодействовать, соединяться друг с другом и создавать единое пространство, невзирая на границы текста.

Литературовед не дифференцирует понятия «мотив» и «лейтмотив», заостряя внимание на их общих чертах - повторяемости и комбинаторике: «...некоторый мотив, раз возникнув, повторяется затем множество раз, выступая при этом каждый раз в новом варианте, новых очертаниях и во все новых сочетаниях с другими мотивами»_(Гаспаров 1994, 30). То есть акцентируется смыслопорождающая функция мотива, что особенно актуально при изучении лирических мотивов, существующих в особой «тесноте» словесного ряда.

Показательно, что «в роли мотива может выступать любой феномен, любое смысловое «пятно» - событие, черта характера, элемент ландшафта, любой предмет, произнесенное слово, краска, звук и т.д.; единственное, что определяет мотив, - это его репродукция в тексте», ... «здесь не существует заданного «алфавита» - он формируется непосредственно в развертывании структуры и через структуру» (Гаспаров 1994, 30). Как видим, Б. Гаспаров отходит от традиционного понимания мотива как минимального звена в сюжете на уровне устойчивой формулы («простейший род мотива может быть выражен формулой a + b» (Веселовский 1989, 78). В его теории мотив выступает не схематичной структурой, а динамическим явлением, которое обладает значительным смыслообразующим потенциалом в формировании 
структуры поэтического мира автора - «сложной конфигурации мотивов» (В.Тюпа).

Данное наблюдение особенно актуально в отношении мотивов в поэтических текстах, которые в силу подвижности, текучести, «мерцания» смыслов не укладываются в жесткие схемы. Отсюда возникает необходимость в адекватном инструментарии, которым, на наш взгляд, является мотивный анализ. «Мотивный анализ утверждает, что никаких уровней вообще нет, мотивы пронизывают текст насквозь и структура текстов напоминает вовсе не кристаллическую решетку (излюбленная метафора лотмановского структурализма), но скорее запутанный клубок ниток» (Руднев 2001, 256).

В противоположность этой тенденции в понимании лирического мотива И. Силантьев предлагает исходить из его собственных сущностных признаков, которые следует соотносить с мотивом повествовательным или эпическим. Такими специфическими признаками он считает лирическое событие и отношения мотива и темы (Силантьев 2011, 109). Также в работах И. Силантьева представлена попытка идентификации мотива через непредикативное слово. В качестве примеров, ссылаясь на существующую исследовательскую практику, автор называет мотив пути, мотив смерти, мотив воды, мотив пустыни, мотив луны. Однако при этом он утверждает, что «либо за непредикативным словом все равно подразумевается комплекс характерно-вероятных действий-предикатов (и тогда за таким означением действительно скрывается повествовательный мотив), либо - и это принципиально иной случай - под мотивом в действительности разумеют тему повествования» (Силантьев 2004, 75). В определенной мере с последним трудно не согласиться.

Действительно, сближение теоретиками-литературоведами понятий «тема» и «мотив» в силу их семантической связи в художественном целом - факт отмеченный неоднократно. Как известно, А. Веселовский под сюжетом понимал «тему, в которой снуются разные положения - мотивы» (Веселовский 1989, 305). Б. Томашевский называет мотив тематической единицей произведения, которая в поэзии воплощается в ведущих темах, символах, сюжетных ситуациях, образах (Томашевский 1996, 136). Подобное явление наблюдается и в исследовательской практике. Показательный пример - статья обобщающего характера «Мотивы поэзии Лермонтова» из «Лермонтовской энциклопедии» (Лермонтовская энциклопедия 1981, 290 312). По наблюдению ее авторов, «мотивами стали называть и характерные для поэта лирические темы или комплекс чувств и переживаний, а также константные свойства его лирического образа, независимо от того, находили ли они соответствующее выражение в какой-либо устойчивой словесной 
формуле» (Лермонтовской энциклопедии 1981, 291). Факт синонимии двух понятий подтверждается ниже: « особо в цикле мотивов выделены ... т.н. вечные темы: время и вечность, любовь и смерть, судьба» (Лермонтовской энциклопедии 1981, 291). Поскольку речь идет о констатации литературоведческой практики вычленения мотивов, авторы теоретической статьи не высказывают своей позиции по данному вопросу, здесь более существенен момент их фиксации в поэзии Лермонтова.

В современном литературоведении особую значимость приобретает такой аспект взаимодействия темы и мотива, как вариативность. Он разрабатывается А. Жолковским и Ю. Щегловым (Жолковский, Щеглов 1996) в русле дихотомической теории мотива, истоки которой в работах А. JI. Бема, А. И. Белецкого, Б. Ярхо, В. Я. Проппа. Как известно, А. Бем, сравнивая варианты мотива, лежащего в основе фабул произведений Пушкина, Лермонтова и Шатобриана, выявляет «семантический инвариант мотива» и его признаки, семантически варьирующие данный мотив. Он их называет «семантическими вариантами». А. Белецкий пишет о двух уровнях реализации мотива в сюжетном повествовании, выделяя «мотив схематический» и «мотив реальный» (см. об этом: Силантьев 2004, 19). В теории мотива А. Жолковского и Ю. Щеглова чрезвычайно важной является постулируемая связь между инвариантными темами и мировосприятием автора как доминанты его поэтического мира: «Инвариантная тема (или инвариантные темы) одного автора - это угол зрения, под которым автор видит все вещи, любимая мысль, которую он вписывает во все свои художественные, а часто и обычные высказывания. С помощью приемов выразительности инвариантная тема писателя воплощается во множестве мотивов, которые также имеют тенденцию к постоянству; эти устойчивые мотивы называются «инвариантными мотивами» данного автора» (Жолковский, Щеглов 1996, 19). Поскольку видение автора - «угол зрения» не ограничивается художественным текстом, следовательно, в определении инвариантных мотивов возможно обращение к факторам внехудожественной реальности. И продолжая рассуждения исследователей, дополним, что семантическое поле инвариантных мотивов (то есть констант поэтического мира автора) создается посредством комбинации мотивов вариантных (то есть переменных, «семантически варьирующих» инвариант).

В статье «К описанию структуры детективной новеллы» Ю. Щеглов определяет место мотивов в поэтике выразительности «в качестве готовых «блоков-полуфабрикатов, используемых на разных этапах деривации». При этом подчеркивается, что «инвариантные мотивы видоизменяются и комбинируются между собой какими-то более сложными и трудноуловимыми 
способами», воплощая «инвариантную тему в совокупности с предметами, выражающими их» (Жолковский, Щеглов 1996, 179). Подобное понимание мотива отменяет жесткую схему анализа поэтического произведения, продуцируя гибкость в подходе к структуре.

В современных исследованиях актуализирован такой аспект, как субъективность интерпретатора в выделении мотива. Субъективность продуцирует такое свойство мотива, как его «нерасчленимо-многозначный, ускользающее-таинственный смысл» (В. Маркович), что особенно характерно для лирики. Иными словами, мотив рассматривается не только как устойчивая формально-содержательная единица художественного текста, но и единица интерпретации, на чем в свое время, но в несколько ином значении настаивал Б. Ярхо. Так, в «A Dictionary of Modern Critical Terms» (1987) под ред. Р. Фаулера зафиксирована многогранная сущность мотива: «... мотив - элемент структурный, так как заставляет увидеть образы в определенной цепи, с другой стороны, мотив - элемент речи, так как вычленяем ритмически. И, наконец, мотив - безусловно, скорее элемент содержательный, нежели формальный, ибо только цепь мотивов как последовательно прерываемое целое несет уникальное значение, которое интерпретатор «собирает». Не повторенный образ не будет иметь такого значения. В конечном счете, структура - это вопрос способности (интерпретатора) к припоминанию» (A Dictionary of Modern Critical Terms 1987). В данном определении привлекает тот факт, что наряду с такими характерными для мотива чертами, как способность проявляться на всех уровнях текста, семантическая значимость, интертекстуальность («образы в определенной цепи»), подчеркивается его «вторичная семантизиция». Особенно важна мысль, согласно которой выделение мотива и его перевод в число концептуально значимых единиц происходит благодаря интерпретационной воле читателя.

В изучении мотива наиболее разработанным аспектом являются его классификации. Они отличаются «пестротой» и многообразием, поскольку основаны на отличных друг от друга принципах, используются в разных методологических контекстах и с разными целями. В теории мотива существуют тематические, онтологические, структурные, предметно-семантические, функциональные классификации, называются мотивы-топосы, мотивы-архетипы, мотивы индивидуальные и т.д. Типологии мотивов могут использоваться в процессе аналитической работы над поэтическим текстом и на уровне теоретических обобщений.

Таким образом, исходя из множества определений мотива и его характеристик, специфики лирического мотива, представляется возможным сформулировать такое понимание лирического мотива: это устойчивая, 
эстетически и семантически значимая единица поэтического произведения, которая содержит характерный для автора комплекс чувств и переживаний, оформленный посредством образа, символа, ключевого слова, понятия. Мотив обладает:

- смысловой целостностью и концептуальностью;

- повторяемостью и узнаваемостью;

- повышенной семантической насыщенностью;

- способностью к модификации;

- вариативностью в различных семантических комбинациях;

- инвариантностью в мотивном репертуаре традиции;

- интертекстуальностью.

В результате анализа могут быть сформированы критерии выделения доминантных мотивов в поэтическом творчестве:

1. Концептуальная и эстетическая значимость в поэтической системе.

2. Семантический потенциал инвариантов и вариантных (конкретизирующих) значений.

3. Повторяемость, взаимообусловленность, пересечение в пределах поэтического мира автора.

4. Устойчивая система образов, символов, ключевых лексем, посредством которых реализуются мотивы.

5. Динамичность в формировании мотивной структуры поэтического мира.

\section{Литература}

A Dictionary of Modern Critical Terms 1987 - A Dictionary of Modern Critical Terms. Ed. by R. Fowler, 1st edition. London: Routledge.

Вершинина 2008 - Н. Вершинина. Система мотивов в поэтическом мире А. А. Фета: автореф. дис. на соискание ученой степени канд. филол. наук: спец. 10.01 .01 - русская литература. Улан-Удэ, 2008. 24 с.

Веселовский 1989 - А. Веселовский. Историческая поэтика. Вступ. ст. И. К. Горского; сост., коммент. В. В. Мочаловой. М.: Высш. шк. 406 с. [Классика литературной науки].

Волкова 2001 - Е. Волкова. Мотив в поэтическом мире автора (на материале поэзии Ф. Ходасевича): дис. ... канд. филол. наук: 10.01.01. Москва. 192 с.

Гаспаров 1994 - Б. Гаспаров. Литературныле лейтмотивы. Очерки по русской литературе XX века. М.: Наука. 304 с. [Восточная литература].

Жолковский, Щеглов 1996 - А. Жолковский, Ю. Щеглов. Pаботь по поэтике выразительности. Инварианть - Тема - Приемь - Текст. Предисл. Б. М. Гаспаров. М.: А. О. Издательская группа «Прогресс». 344 с.

Иванова 2004 - Т. Иванова. Мифологема и мотив (к вопросу о фольклористической терминологии) [электронный ресурс] / Комплексное собирание, систематика, экспериментальная текстология. Вып. 2: Материаль VI Международной школьь молодого фольклориста (22-24 ноября 2003 года). Отв. ред. В. М. Гацак, Н. В. Дранникова. 222 с. Режим доступа: http://folk.pomorsu.ru/index.php?page=booksopen\&book=6\&book_ 
sub $=6 \_1$

Костина-Кассанелли 2013 - О. Костина-Кассанелли. Конщепт и мотив: междисциплинарная соотнесенность понятий [электронный ресурс]. Вісник Харківського національного університету ім. В. Н. Каразіна, 1048. Сер.: Філологія, 67, 59-63. Режим доступа: http:// dspace.univer.kharkov.ua/handle/123456789/8515

Лермонтовская энциклопедия 1981 - Лермонтовская энциклопедия. АН СССР. Ин-т рус. лит. (Пушкин. Дом). Науч.-ред. совет изд-ва «Сов. энцикл.». Гл. ред. В. А. Мануйлов. М.: Сов. энциклопедия. 746 с.

Литературный энциклопедический словарь 1987 - Литературный энциклопедический словарь. Под общ. ред. В. М. Кожевникова, П. А. Николаева. М.: Сов. энциклопедия. $752 \mathrm{c}$.

Литературная энциклопедия терминов и понятий 2003 - Литературная энциклопедия терминов и понятий. Под. ред. А. Н. Николюкина. Институт научн. информации по общественным наукам РАН. М.: НПК «Интелвак». 1600 с.

Літературознавча енциклопедія 2007 - Літературознавча енциклопедія. У 2-х т. Авт.-уклад. Ю. І. Ковалів. К.: ВЦ «Академія», Т. 1. 2007. 608 с.; Т. 2. 2007. 624 с. [Енциклопедія ерудита].

Лотман 2005 - Ю. Лотман. Об искусстве. СПб.: «Искусство - СПБ». 704 с.

Меднис 2013 - Н. Е. Меднис. Мотив воды в романе Достоевского «Преступление и наказание». In Меднис, Н. Е., Поэтика и семиотика русской литературы [Сер. Коммуникативные стратегии культуры]. [Электронный ресурс]. Режим доступа: file:///D; /загрузки \%20 из $\% 20$ интернета/-books-download-pdf-544752-poetika-i-semiotika-russkoy-literatury.pdf

Неклюдов 2004 - С. Неклюдов. Мотив и текст. In Язык культуры: семантика и грамматика. К 80-летию со дня рождения академика Никиты Ильича Толстого (1923-1996). Отв. ред. С. М. Толстая (с. 236-247). М.: Индрик, 2004.

Пахарева 1994 - Т. Пахарева. Художественная система Аннь Ахматовой: навч. посібник із спецкурсу. К.: ІСДО, 1994. 140 с.

Руднев 2001 - В. Руднев. Мотивный анализ. In Энциклопедический словарь культуры ХХ в. М.: Аграф. 608 c.

Силантьев 2004 - И. Силантьев. Поэтика мотива. М.: Языки славянской культуры. 296 с.

Силантьев 2011 - И. Силантьев. Лирический мотивный комплекс. In Сюжетно-мотивные комплексы русской литературы: коллективная монография (с. 106-114). Новосибирск: Академическое издательство Гео.

Томашевский 1996 - Б. Томашевский. Теория литературы. Поэтика: учеб. пособие. Вступ. статья Н. Д. Тамарченко; комм. С. Н. Бройтмана. М.: Аспект Пресс. 334 с.

Хализев 2000 - В. Хализев. Теория литературы: учебник для вузов. 2-е изд. М.: Высшая школа. 398 с.

Эпштейн 1997 - М. Эпштейн. Образ. In Литературный энциклопедический словарь. Под общ. ред. В. М. Кожевникова, П. А. Николаева (с. 252-256). М.: Сов. энциклопедия.

Ярхо 2006 - Б. Ярхо. Методология точного литературоведения: избранные труды по теории литературы. Изд. подгот. М. В. Акимова, И. А. Пильщиков и М. И. Шапир. Под общей ред. М. И. Шапира. М.: Языки славянских культур. 927 с. 


\section{Nataliia Lytovchenko}

Summary

The article examines modern theories of motif, the conceptual apparatus of the problem field 'motif', and the immanent nature of the poetic text; and if the specific functioning of the term 'motif' has been analysed in the system of literary categories.

The analysis in the study suggests that the theory of motif is represented mainly by several concepts and their 'variations', taking into account the evolution of this category. This is a semantic theory, originating in the historical poetics of A. Veselovsky, and the later dichotomous, structural-semantic, thematic, intertextual and pragmatic theories of motif.

Based on the many definitions of the motif and its characteristics, the specification of the lyrical motif, the article formulates an understanding of the lyrical motif as a stable, aesthetic and semantically significant unit of poetic work, which contains a characteristic complex of feelings and experiences, framed through an image, symbol, key word, or concept. The article proves that the motif has:

- meaning integrity and conceptuality;

- repeatability and recognisability;

- $\quad$ increased semantic saturation;

- $\quad$ the ability to modify;

- variability in different semantic combinations;

- invariance in the motif repertoire of tradition;

- intertextuality.

As a result of the literary analysis, criteria for highlighting dominant motifs are formed in the artist's poetic work:

1. Conceptual and aesthetic significance in the poetic system;

2. Semantic potential of invariants and variant (specific) values;

3. Repetition, mutual conditioning, intersection in the poetic world of the author;

4. A sustainable system of images, symbols, key lexes, through which motifs are realised;

5. Dynamics in the formation of the motif structure of the poetic world. 